\title{
Improvements and Gaps in Financial Risk Protection Among Veterans Following the Affordable Care Act
}

\author{
Charles Liu, MD, MS ${ }^{1,2,3}$, Christopher A. Scannell, MD, PhD ${ }^{2,3}$, \\ Tiffany Kenison, MD, MPH, MTS $2,3,4$, Sherry M. Wren, $\mathrm{MD}^{1,5}$, and Debra Saliba, MD, MPH ${ }^{3,6}$
}

'Department of Surgery, Stanford University School of Medicine, Stanford, CA, USA; ${ }^{2}$ National Clinician Scholars Program, University of California Los Angeles, Los Angeles, CA, USA; ${ }^{3}$ Veterans Health Administration, Greater Los Angeles Healthcare System, Los Angeles, CA, USA; ${ }^{4}$ Los Angeles County + University of Southern California Medical Center, Los Angeles, CA, USA; ${ }^{5}$ Veterans Health Administration, Palo Alto Healthcare System, Palo Alto, CA, USA; ${ }^{6}$ Borun Center for Gerontological Research, David Geffen School of Medicine at UCLA, Los Angeles, CA, USA.

BACKGROUND: Despite public perception, most of the nearly 20 million US veterans have health coverage outside the Veterans Health Administration (VHA), and VHA eligibility and utilization vary across veterans. Out-ofpocket healthcare spending thus remains a potential source of financial hardship for veterans. The Affordable Care Act (ACA) aimed to expand health insurance access, but its effect on veterans' financial risk protection has not been explored.

OBJECTIVE: To evaluate whether ACA implementation was associated with changes in veterans' risk of catastrophic health expenditures, and to characterize drivers of catastrophic health spending among veterans postACA.

DESIGN: Using multivariable linear probability regression, we examined changes in likelihood of catastrophic health spending after ACA implementation, stratifying by age (18-64 vs 65+), household income tercile, and payer (VHA vs non-VHA). Among veterans with catastrophic spending post-ACA, we evaluated sources of out-ofpocket spending.

PARTICIPANTS: Nationally representative sample of 13,030 veterans aged 18+ from the 2010 to 2017 Medical Expenditure Panel Survey.

INTERVENTION: ACA implementation, January 1, 2014. MAIN MEASURES: Likelihood of catastrophic health expenditures, defined as household out-of-pocket spending exceeding $10 \%$ of household income.

KEY RESULTS: Among veterans aged 18-64, ACA implementation was associated with a $26 \%$ decrease in likelihood of catastrophic health expenditures (absolute change, -1.4 percentage points [pp]; 95\% CI, -2.6 to $-0.2 ; p=0.03$ ), which fell from $5.4 \%$ pre-ACA to $3.9 \%$ post-ACA. This was driven by a $38 \%$ decrease in catastrophic spending among veterans with non-VHA coverage (absolute change, $-1.8 \mathrm{pp} ; 95 \% \mathrm{CI},-3.0$ to -0.6 ; $p=0.003)$. In contrast, catastrophic expenditure rates among veterans aged 65+ remained high, at $13.0 \%$ preand $12.5 \%$ post-ACA. Major drivers of veterans' spending

Abstract accepted for presentation at the AcademyHealth Annual Research Meeting, Boston, MA, June 2020 (in-person meeting cancelled due to COVID-19).

Received November 30, 2020

Accepted April 3, 2021

Published online May 6, 2021
post-ACA include dental care, prescription drugs, and home care.

CONCLUSIONS: ACA implementation was associated with reduced household catastrophic health expenditures for younger but not older veterans. These findings highlight gaps in veterans' financial protection and areas amenable to policy intervention.

KEY WORDS: veterans; out-of-pocket spending; catastrophic health expenditures; Affordable Care Act; insurance expansion; uninsured; underinsured.

J Gen Intern Med 37(3):573-81

DOI: $10.1007 / \mathrm{s} 11606-021-06807-4$

(c) Society of General Internal Medicine 2021

\section{INTRODUCTION}

Per capita out-of-pocket healthcare expenditures have steadily increased in the USA over the last 50 years. ${ }^{1}$ An estimated 1 in 4 Americans report difficulty affording medical bills, ${ }^{2}$ and healthcare-related expenses are the leading cause of household bankruptcy. ${ }^{3,4}$ To address these issues, the Patient Protection and Affordable Care Act (ACA) was enacted in 2010 and aimed to expand health insurance coverage and lower the cost of care. ${ }^{5}$ Approximately 20 million Americans gained coverage through the ACA, ${ }^{6}$ primarily through Medicaid expansion and the ACA insurance Marketplaces. ${ }^{7,8}$ These provisions have been associated with decreases in cost-related care delays and trouble paying medical bills, based on patient report. ${ }^{9,10}$ More directly, analyses of patient expenditures have shown an association between ACA implementation and decreased outof-pocket spending as well as risk of catastrophic health expenditures. $^{11-15}$

Veterans have different options for healthcare financing than the broader US population. For example, through the Veterans Health Administration (VHA), veterans with a service-related condition or meeting income eligibility thresholds may qualify for care with minimal to no cost sharing. ${ }^{16}$ However, less than half of all veterans are enrolled in VHA coverage, ${ }^{17}$ fewer than a third use VHA healthcare annually, ${ }^{18}$ and many remain uninsured or rely on private or other government insurance, which 
often require patients to pay greater out-of-pocket costs. ${ }^{19}$ Furthermore, veterans as a group have characteristics that increase their health-related financial risk, including higher rates of posttraumatic stress disorder, depression, and anxiety ${ }^{20,21}$; higher likelihood of residing in rural areas farther from sources of care ${ }^{22,23}$; and higher likelihood of residing in the South census region, where only $12 \%$ of the population lives in Medicaid expansion states. $^{24}$

Although studies show that the uninsured rate fell among veterans following ACA implementation, ${ }^{22,25,26}$ no studies to date have examined the impact of the law on veterans' exposure to healthcare-related financial risk. We thus sought to assess the association between ACA implementation and changes in veterans' rates of catastrophic out-of-pocket spending, both nationally and across age and income strata, and to characterize the drivers of catastrophic expenditures among veterans in the post-ACA period.

\section{METHODS}

\section{Data and Study Population}

We analyzed data from the Medical Expenditure Panel Survey (MEPS), a nationally representative survey of healthcare use and expenditures for the US civilian noninstitutionalized population. ${ }^{27}$ MEPS collects data on outof-pocket spending, premium contributions, income, and demographics from about 15,000 households per year, interviewing each household five times over a 2-year period and enrolling new households annually. Information from respondents is supplemented with data from medical providers and pharmacies to produce highly valid expenditure estimates. Our analysis includes spending data collected from January 1, 2010, to December 31, 2017, for all types of healthcare services captured in MEPS, including inpatient stays, outpatient and emergency department visits, prescription drugs, home healthcare (from agency, non-agency, and informal providers), dental services, vision aids, and durable medical equipment. As MEPS excludes data from any period during which an individual is institutionalized, spending for short- and long-term nursing home care is not included.

Our study population included all US adults aged 18+ who were honorably discharged from the military ("veterans"). We stratified veterans into younger (18 to 64 years) and older (65+) age groups, which have different healthcare needs and were affected differently by ACA reforms, with most coverage expansion under the law targeted to the younger age group. Additionally, we divided the two age groups into household income terciles and determined each veteran's primary payer (see eMethods for details). Because full ACA implementation began on January 1,2014 , we defined the pre- and post-ACA periods as 2010-2013 and 2014-2017, respectively. ${ }^{5}$

\section{Definition of Catastrophic Health Expenditures}

To quantify financial burden, we summed calendar-year outof-pocket spending for all members of the veteran's family and divided by their combined income, as families share costs and resources. We then defined catastrophic health expenditures as out-of-pocket spending exceeding $10 \%$ of family income, a widely used threshold to define unaffordable expenditures and underinsurance. ${ }^{11,28}$ We used the Current Population Survey (CPS) definition of a family - individuals living together and related by birth, marriage, or adoption ${ }^{29}$ - which the Census Bureau uses to determine poverty thresholds. ${ }^{30}$ All expenditures and incomes were converted to 2017 dollars using the Consumer Price Index..$^{31,32}$

\section{Statistical Analysis}

We examined the association between ACA implementation and financial protection by fitting a multivariable linear probability regression model to the binary outcome of catastrophic expenditures, regressing this on a binary indicator for the postACA time period and adjusting for age, gender, race/ethnicity, marital status, employment status, self-reported health status, census region, and family size. We used a linear probability model to allow for direct interpretation of regression coefficients and to align our methods with those of existing studies. ${ }^{9}{ }^{15}$ MEPS survey weights, strata, and clusters were used to account for the complex survey design, and cluster-robust standard errors were employed to account for correlation within each sampling unit (group of neighboring counties).

All analyses were conducted using Stata 16.1 (College Station, TX). This study was exempted from review by the University of California, Los Angeles Institutional Review Board.

\section{Sensitivity Analyses}

We conducted several sensitivity analyses: (1) using a logistic regression model rather than a linear probability model to analyze the likelihood of catastrophic expenditures, (2) using the MEPS rather than the CPS definition of family, which includes nonmarried partners, foster children, and in-laws, and (3) using an alternate definition of catastrophic expenditures as out-of-pocket plus premium spending exceeding $19.5 \%$ of family income (the sum of the $10 \%$ out-of-pocket spending threshold and a $9.5 \%$ income threshold for high-burden premiums, based on an ACA provision allowing individuals whose employer-based premiums exceed $9.5 \%$ of income to purchase Marketplace insurance). ${ }^{33}$

\section{RESULTS}

\section{Baseline Characteristics}

Our study population included 13,030 veteran survey respondents, representing about 19.5 million veterans per year after 
survey weighting. Of these, 6968 (53\%) were aged 18 to 64 years and $6062(47 \%)$ were aged $\geq 65$ years, representing 9.7 and 9.8 million veterans per year, respectively. Among adults aged 18-64, veterans were more likely than non-veterans to be male, White or Black, married, from the South, and to have worse self-reported health (Table 1). They were also more likely than non-veterans to be insured pre-ACA. Similar differences existed among adults over 65, except that veterans had better self-reported health than non-veterans and were less likely to be Black.

\section{Changes in Primary Payer}

The uninsured rate among US veterans aged 18-64 declined from $17 \%$ in 2010 to $12 \%$ in 2017 . Over the same period, the share of younger veterans with the VHA as primary payer increased from 10 to $12 \%$, Tricare from 4 to $8 \%$, and Medicare or Medicaid from 6 to $8 \%$, while the share with private insurance decreased from 55 to $51 \%(p<0.001$ for overall change in payer mix; Fig. 1a). Among veterans aged 65 and older, the uninsured rate remained low at $1 \%$. The primary payer mix among older veterans also remained relatively stable, with Medicare or Medicaid remaining the leading primary payer $(60 \%$ in 2010 vs $64 \%$ in 2017$)$, followed by private insurance (19\% vs $18 \%$ ), the VHA (16\% vs $14 \%$ ), and
Tricare ( $4 \%$ vs $2 \%$ ) ( $p=0.52$ for overall change in payer mix; Fig. 1b).

\section{Changes in Number of Veterans Experiencing Catastrophic Health Expenditures}

The annual incidence of catastrophic health expenditures among veterans aged 18-64 declined from 545 per 10,000 pre-ACA to 391 per 10,000 post-ACA (Fig. 2). This primarily reflected a decrease in the number of veterans experiencing catastrophic family spending who were uninsured (162 per 10,000 pre-ACA vs 103 per 10,000 post-ACA) or privately insured (199 vs 98). The number of younger veterans with VHA, Medicare, or Medicaid coverage who experienced catastrophic expenditures was largely stable pre- vs post-ACA (57 vs 60 for VHA; 64 vs 65 for Medicare/Medicaid).

In contrast, the annual incidence of catastrophic family spending among veterans over age 65 was higher than among younger veterans and remained largely unchanged, at 1301 per 10,000 pre-ACA and 1250 per 10,000 post-ACA (Fig. 2). Among older veterans experiencing catastrophic expenditures, the most common primary payer was Medicare or Medicaid ( 924 per 10,000 pre-ACA vs 979 per 10,000 post-ACA), followed by private insurance (189 vs 143), VHA (167 vs 101), and Tricare (12 vs 21). Notably, Medicare or Medicaid

Table 1 Baseline Characteristics of Adult Veterans and Non-Veterans in the United States Prior to Implementation of the Affordable Care Act, 2010-2013. (Values in table represent weighted mean (standard deviation) or weighted \%)

\begin{tabular}{|c|c|c|c|c|c|c|}
\hline \multirow[t]{2}{*}{ Characteristic } & \multicolumn{3}{|l|}{ Ages 18-64 } & \multicolumn{3}{|l|}{ Ages 65+ } \\
\hline & $\begin{array}{l}\text { Veterans } \\
(n=3823)\end{array}$ & $\begin{array}{l}\text { Non-veterans } \\
(n=82,953)\end{array}$ & $p$-value & $\begin{array}{l}\text { Veterans } \\
(n=2977)\end{array}$ & $\begin{array}{l}\text { Non-veterans } \\
(n=13,043)\end{array}$ & $p$-value \\
\hline US weighted population (per year) & $10,438,407$ & $182,423,137$ & & $9,698,518$ & $32,970,219$ & \\
\hline Age (years) & $49.8(9.9)$ & $40.2(13.3)$ & $<0.001$ & $74.9(5.7)$ & $73.9(6.2)$ & $<0.001$ \\
\hline Female $(\%)$ & 10.4 & 53.2 & $<0.001$ & 2.8 & 71.3 & $<0.001$ \\
\hline \multicolumn{7}{|l|}{ Race/ethnicity (\%) } \\
\hline Non-Hispanic White & 75.0 & 63.0 & \multirow[t]{4}{*}{$<0.001$} & 89.6 & 75.4 & \multirow[t]{4}{*}{$<0.001$} \\
\hline Non-Hispanic Black & 14.2 & 12.1 & & 5.7 & 9.5 & \\
\hline Hispanic & 6.3 & 17.0 & & 2.4 & 8.9 & \\
\hline Other/multiple & 4.5 & 7.9 & & 2.3 & 6.3 & \\
\hline \multicolumn{7}{|l|}{ Marital status (\%) } \\
\hline Married & 62.3 & 51.5 & \multirow[t]{3}{*}{$<0.001$} & 67.3 & 51.4 & \multirow[t]{3}{*}{$<0.001$} \\
\hline Divorced/separ./wid. & 24.7 & 14.8 & & 29.3 & 44.2 & \\
\hline Never married & 13.0 & 33.6 & & 3.3 & 4.4 & \\
\hline \multicolumn{7}{|l|}{ Census region $(\%)$} \\
\hline Northeast & 13.6 & 18.4 & \multirow{4}{*}{$<0.001$} & 17.4 & 19.6 & \multirow[t]{4}{*}{0.04} \\
\hline Midwest & 21.2 & 21.3 & & 22.8 & 22.0 & \\
\hline South & 42.7 & 36.7 & & 39.7 & 36.4 & \\
\hline West & 22.6 & 23.7 & & 20.2 & 22.0 & \\
\hline Employed (\%) & 77.8 & 78.2 & 0.73 & 23.3 & 20.8 & 0.07 \\
\hline Family income (2017 dollars) & $80,175(54,531)$ & $78,230(65,278)$ & 0.22 & $69,724(49,993)$ & $60,440(55,785)$ & $<0.001$ \\
\hline Family size & $2.6(1.3)$ & $3.0(1.6)$ & $<0.001$ & $1.9(0.6)$ & $2.0(1.0)$ & 0.001 \\
\hline \multicolumn{7}{|l|}{ Self-reported health (\%) } \\
\hline Excellent/v. good/good & 84.6 & 88.8 & \multirow[t]{3}{*}{$<0.001$} & 80.5 & 78.3 & \multirow[t]{3}{*}{$<0.001$} \\
\hline Fair/poor & 15.2 & 11.1 & & 17.6 & 20.6 & \\
\hline Unknown & 0.2 & 0.2 & & 2.0 & 1.1 & \\
\hline \multicolumn{7}{|l|}{ Primary payer (\%) } \\
\hline Medicare & 3.2 & 2.8 & \multirow[t]{8}{*}{$<0.001$} & 63.8 & 76.5 & \multirow[t]{8}{*}{$<0.001$} \\
\hline Medicaid & 2.2 & 6.8 & & 0.5 & 2.4 & \\
\hline Private & 51.1 & 56.7 & & 17.1 & 16.4 & \\
\hline VHA & 10.2 & 0.1 & & 12.8 & 0.4 & \\
\hline Tricare & 5.7 & 0.6 & & 3.3 & 1.1 & \\
\hline Other/unknown & 2.6 & 2.9 & & 1.1 & 1.3 & \\
\hline Trans. unins. (1-5 mo) & 6.5 & 6.6 & & 0.7 & 0.9 & \\
\hline Uninsured $(\geq 6 \mathrm{mo})$ & 18.5 & 23.4 & & 0.7 & 1.2 & \\
\hline
\end{tabular}




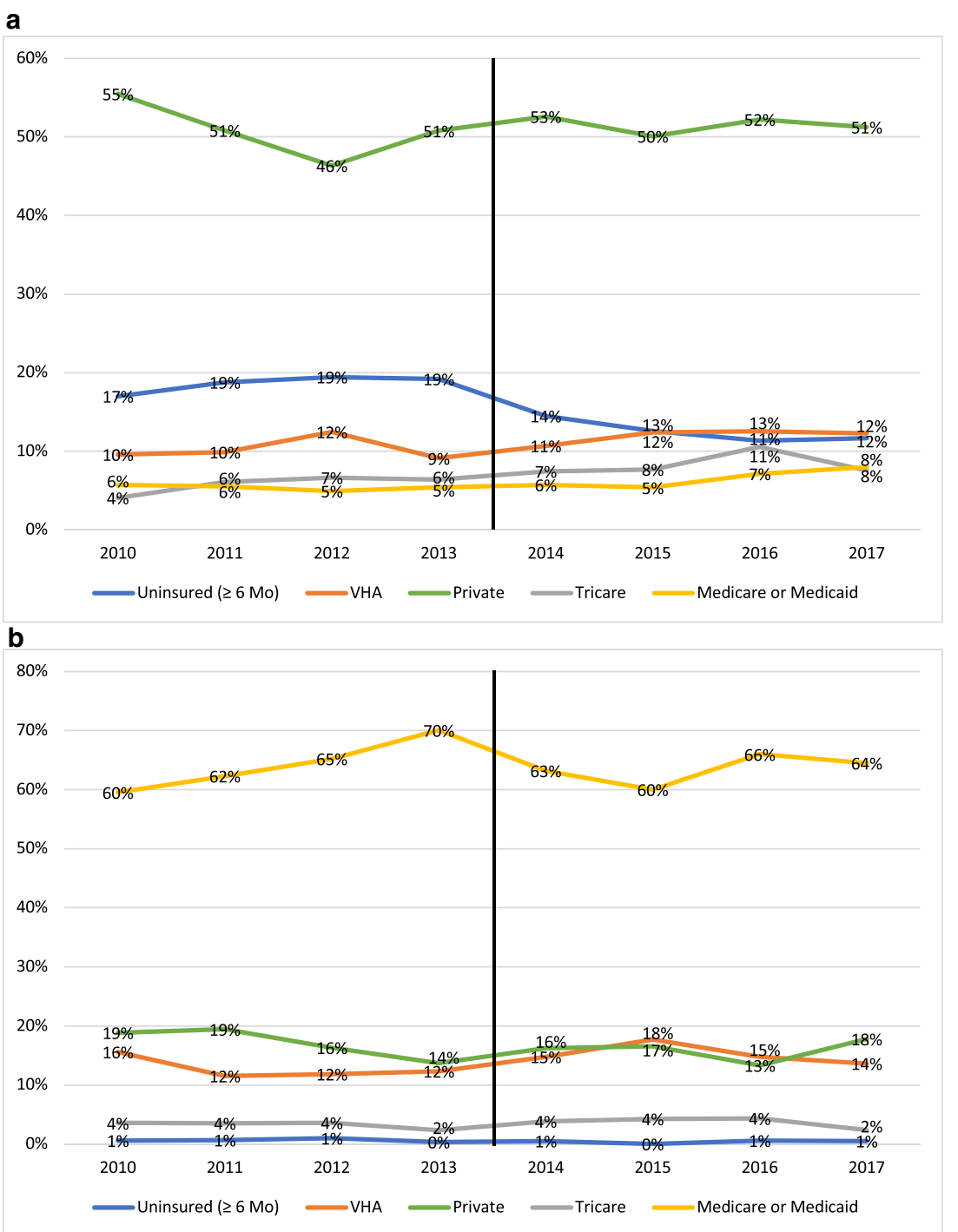

Figure 1 Primary payer type by year, US veterans (a) aged 18-64, (b) aged 65+. Vertical line $=$ ACA implementation. VHA $=$ Veterans Health Administration. For clarity, only selected payer groups are shown.

was even more likely to be the primary payer for older veterans with catastrophic expenditures (75\% over the full study period) than for older veterans overall $(64 \%)$. On average, no more than 5 per 10,000 older veterans each year were uninsured or transiently uninsured and experienced catastrophic expenditures, both pre- and post-ACA.

\section{Association of ACA Implementation with Changes in Likelihood of Catastrophic Health Expenditures}

In our multivariable analysis of veterans aged 18-64 (Table 2), ACA implementation was associated with a $26 \%$ decrease in the likelihood of catastrophic expenditures (absolute change, -1.4 percentage points [pp]; $95 \% \mathrm{CI},-2.6$ to $-0.2 ; p=0.03$ ). This was driven primarily by a $27 \%$ decrease in catastrophic family spending among low-income veterans (absolute change, $-3.7 \mathrm{pp} ; 95 \% \mathrm{CI},-6.6$ to $-0.7 ; p=0.02$ ) and a $38 \%$ decrease among veterans with non-VHA coverage (absolute change, $-1.8 \mathrm{pp} ; 95 \% \mathrm{CI},-3.0$ to $-0.6 ; p=0.003)$. In contrast, middle- and high-income veterans, as well as those with VHA as primary payer or who were uninsured, experienced no significant change in catastrophic family spending rates. Notably, low-income younger veterans with VHA as primary payer had substantially lower pre-ACA catastrophic family spending rates than those with non-VHA coverage $(10.0 \%$ vs $16.3 \%$ ). After ACA implementation, low-income veterans with non-VHA coverage experienced a $40 \%$ decrease in catastrophic family spending (absolute change, $-6.5 \mathrm{pp} ; 95 \% \mathrm{CI}$, -10.5 to $-2.5 ; p=0.002$ ), bringing their catastrophic expenditure rates on par to those among veterans with VHA coverage (9.6\% VHA vs $9.3 \%$ non-VHA).

Among veterans over age 65 (Table 2), ACA implementation was not associated with a change in likelihood of catastrophic expenditures overall or in any income tercile. However, older veterans with VHA as primary payer saw a $46 \%$ decrease in catastrophic family spending (absolute change, 


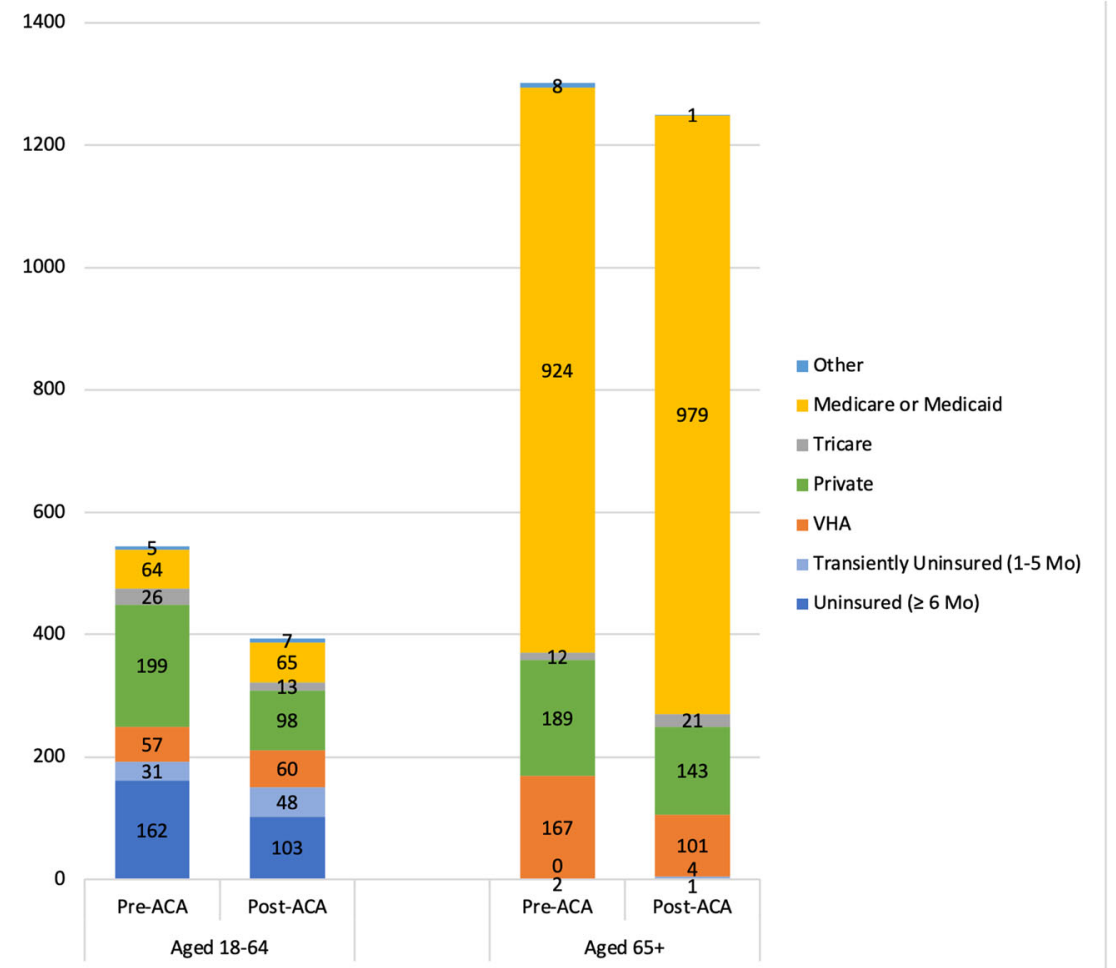

Figure 2 Number of veterans per 10,000 experiencing catastrophic health expenditures annually pre- vs post-ACA, by age group and primary payer. VHA = Veterans Health Administration.

Table 2 Association Between ACA Implementation and Changes in Likelihood of Catastrophic Health Expenditures Among US Veterans, by Age, Income, and Primary Payer

\begin{tabular}{|c|c|c|c|c|c|}
\hline & $\begin{array}{l}\text { Median family income pre- } \\
\text { ACA }\end{array}$ & $\begin{array}{l}\text { Likelihood of } \\
\text { CHE } \\
\text { pre-ACA }\end{array}$ & $\begin{array}{l}\text { Likelihood of } \\
\text { CHE } \\
\text { post-ACA }\end{array}$ & $\begin{array}{l}\text { Adjusted change in likelihood, } \\
\text { pp }\end{array}$ & $95 \% \mathrm{CI}$ \\
\hline $\begin{array}{l}\text { Veterans aged } 18- \\
64\end{array}$ & $\$ 66,406$ & $5.4 \%$ & $3.9 \%$ & $-1.4^{*}$ & $-2.6,-0.2$ \\
\hline \multicolumn{6}{|l|}{ By income tercile } \\
\hline Low & $\$ 28,246$ & $13.5 \%$ & $10.1 \%$ & $-3.7 *$ & $-6.6,-0.7$ \\
\hline Middle & $\$ 64,293$ & $1.8 \%$ & $1.4 \%$ & -0.4 & $-1.4,+0.7$ \\
\hline High & $\$ 120,959$ & $1.1 \%$ & $0.3 \%$ & -0.7 & $-1.4,+0.0$ \\
\hline \multicolumn{6}{|l|}{ By primary payer } \\
\hline VHA & $\$ 52,314$ & $5.6 \%$ & $5.0 \%$ & -0.3 & $-3.3,+2.8$ \\
\hline Non-VHA & $\$ 82,522$ & $4.7 \%$ & $2.7 \%$ & $-1.8 * *$ & $-3.0,-0.6$ \\
\hline Uninsured & $\$ 37,535$ & $8.7 \%$ & $8.2 \%$ & -0.2 & $-4.2,+3.9$ \\
\hline \multicolumn{6}{|c|}{ By primary payer in low-income tercile } \\
\hline VHA & $\$ 23,974$ & $10.0 \%$ & $9.6 \%$ & -1.2 & $-6.6,+4.1$ \\
\hline Non-VHA & $\$ 32,299$ & $16.3 \%$ & $9.3 \%$ & $-6.5 * *$ & $\begin{array}{l}-10.5 \\
-2.5\end{array}$ \\
\hline Uninsured & $\$ 22,899$ & $13.4 \%$ & $11.0 \%$ & -2.3 & $-7.8,+3.2$ \\
\hline \multicolumn{6}{|l|}{ By income tercile } \\
\hline Low & $\$ 22,336$ & $28.3 \%$ & $26.0 \%$ & -1.0 & $-6.1,+4.0$ \\
\hline Middle & $\$ 51,492$ & $8.3 \%$ & $8.6 \%$ & +0.3 & $-2.8,+3.5$ \\
\hline High & $\$ 110,476$ & $2.7 \%$ & $3.0 \%$ & +0.2 & $-1.6,+2.0$ \\
\hline \multicolumn{6}{|l|}{ By primary payer } \\
\hline VHA & $\$ 38,818$ & $13.1 \%$ & $6.6 \%$ & $-6.0 *$ & \multirow{2}{*}{$\begin{array}{l}-10.7 \\
-1.2 \\
-1.9,+3.0\end{array}$} \\
\hline Non-VHA & $\$ 56,015$ & $13.3 \%$ & $13.7 \%$ & +0.5 & \\
\hline \multicolumn{6}{|c|}{ By primary payer in low-income tercile } \\
\hline VHA & $\$ 22,096$ & $22.7 \%$ & $12.2 \%$ & $-9.5 *$ & \multirow{2}{*}{$\begin{array}{l}-18.2, \\
-0.9 \\
-5.0,+6.4\end{array}$} \\
\hline Non-VHA & $\$ 22,482$ & $30.1 \%$ & $29.7 \%$ & +0.7 & \\
\hline
\end{tabular}

$*_{p}<0.05, *^{*} p<0.01 . p p=$ percentage points, $C H E=$ catastrophic health expenditures, VHA = Veterans Health Administration. Non-VHA includes Medicare, Medicaid, private insurance, and Tricare. Both VHA and non-VHA refer to individuals with year-round insurance coverage. Uninsured not shown for veterans aged $65+$ due to small cell sizes 
$-6.0 \mathrm{pp} ; 95 \% \mathrm{CI},-10.7$ to $-1.2 ; p=0.01)$, bringing their postACA level down to less than half of that seen among veterans with non-VHA coverage (6.6\% VHA vs $13.7 \%$ non-VHA). Similarly, low-income older veterans with VHA as primary payer saw catastrophic family spending decrease by $42 \%$ (absolute change, $-9.5 \mathrm{pp} ; 95 \% \mathrm{CI},-18.2$ to $-0.9 ; p=0.03$ ), further lowering their post-ACA catastrophic spending levels beyond those conferred by non-VHA coverage (12.2\% VHA vs $29.7 \%$ non-VHA).

\section{Sources of Health Spending Among Veterans with Catastrophic Expenditures Post-ACA Implementation}

Focusing on the veteran's expenditures only, sources of outof-pocket spending differed substantially by primary payer among veterans who experienced catastrophic family spending post-ACA (Fig. 3, Supplement eTable 3). Among veterans aged 18-64 with VHA as primary payer, out-of-pocket spending was driven primarily by outpatient visits ( $73 \%)$, followed by prescription drugs $(11 \%)$ and dental care (11\%). In contrast, younger veterans with non-VHA primary payers had spending driven primarily by prescription drugs (38\%) and dental care (29\%), with a smaller contribution from outpatient visits $(22 \%)$. Finally, uninsured younger veterans' spending was more evenly divided between inpatient stays (26\%), outpatient visits (26\%), prescription drugs (19\%), and vision aids (14\%).

Among veterans over age 65 who experienced catastrophic family spending and had VHA as primary payer, the largest sources of spending were home healthcare (26\%), dental care $(21 \%)$, and prescription drugs $(17 \%)$. Older veterans with catastrophic family spending and non-VHA primary payers similarly saw their spending driven by dental (23\%) and home healthcare (22\%), although they also spent substantially on outpatient visits (18\%).

\section{Sensitivity Analyses}

Using a logistic regression model in place of a linear probability model and using the MEPS definition of family did not qualitatively affect our results (Supplement eTables 1-2). When we used an alternate definition of catastrophic expenditures that included premiums, we still observed a trend toward lower catastrophic spending post-ACA among younger veterans in the income and payer strata described above, but these decreases fell short of statistical significance.

\section{DISCUSSION}

Using a nationally representative sample of US veterans, we found that implementation of the ACA in 2014 was associated with $26 \%$ lower likelihood of catastrophic family health expenditures among veterans aged 18-64, but no significant change in catastrophic spending among veterans over age
65. Our findings build on prior work showing that ACA implementation was associated with a $21 \%$ decrease in catastrophic health spending among all adults aged 18-64, suggesting that veterans experienced greater improvements in financial protection than the general public. ${ }^{11}$ Despite some gains, financial burdens faced by veterans remain substantial, with 1 in 25 younger veterans and 1 in 10 who are low-income experiencing catastrophic family spending each year after ACA implementation. Financial risk is more than twice as high among veterans over 65 , with 1 in 8 older veterans and 1 in 4 who are low-income experiencing catastrophic family spending annually post-ACA. These findings suggest that while the ACA was associated with substantially improved insurance coverage for younger veterans, much work remains in achieving one of the key aims of coverage: providing financial risk protection.

Several possible reasons exist for the observed decline in household catastrophic spending among veterans aged 18-64. First, the uninsured rate among younger veterans fell by nearly a third over the study period, with concomitant increases in Medicaid, VHA, and Tricare coverage. One facilitator of this was likely Medicaid expansion, with about 256,000 uninsured veterans living in the Medicaid expansion states of California, Ohio, Illinois, Pennsylvania, and Michigan alone in 2012. ${ }^{18}$ Future research comparing financial outcomes of veterans living in Medicaid expansion vs non-expansion states would shed further light on this possibility. Additionally, the ACA's individual mandate to purchase health insurance prompted already eligible veterans to enroll in VHA, Medicaid, and Tricare health benefits. ${ }^{8}$ Since VHA and Medicaid coverage have little to no cost sharing, ${ }^{16,34}$ these enrollments likely contributed to decreases in catastrophic expenditures. Third, the Veterans Choice Act of 2014, which expanded opportunities for veterans of all ages to use VHA benefits at non-VHA facilities, may have increased utilization of VHA coverage, although further research is needed to evaluate this multifaceted legislation. Between late 2014 and early 2017, about 17\% of all users of VHA healthcare did so at community sites through the Veterans Choice Program. ${ }^{35}$ Finally, the sizable decrease in catastrophic expenditures among younger veterans with non-VHA coverage may be attributable to the ACA's reforms to the private insurance market, including the creation of insurance Marketplaces offering subsidized plans,${ }^{36}$ guaranteed issue and community rating rules that prohibited denying or overcharging veterans with pre-existing conditions, ${ }^{37}$ and stricter out-of-pocket spending limits. ${ }^{5,38}$

In contrast to most prior studies, we also examined veterans aged 65 and older, who are traditionally thought to have universal coverage through Medicare, Medicaid, and VHA benefits. Despite very low uninsured rates, the incidence of household catastrophic spending among older veterans far exceeded that among younger veterans, with more than 1.2 million veterans over age 65 paying catastrophic bills annually both pre- and post-ACA. Notably, the majority of these relied on Medicare or Medicaid as their primary payer, highlighting 


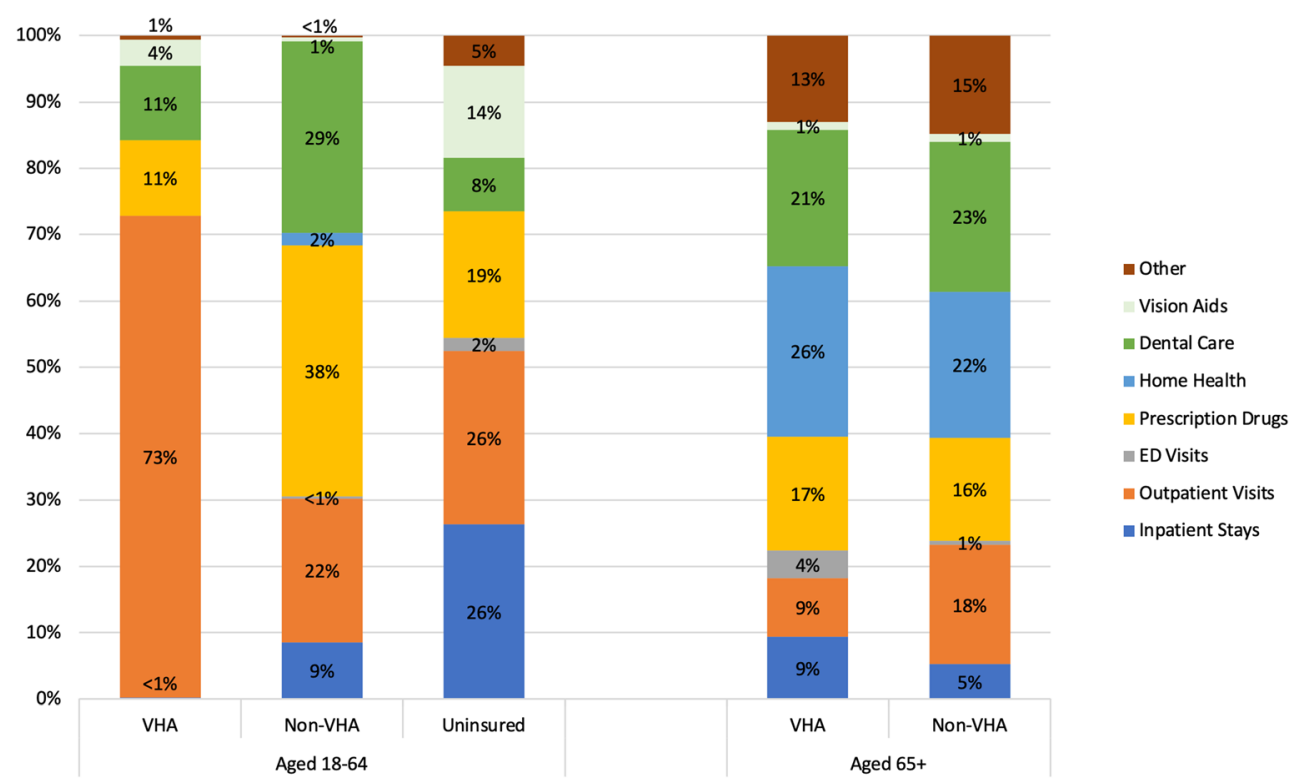

Figure 3 Sources of out-of-pocket spending among veterans with catastrophic spending in post-ACA period, by age group and primary payer. VHA = Veterans Health Administration. Non-VHA includes Medicare, Medicaid, private insurance, and Tricare. ED = emergency department. Other includes durable medical equipment. Uninsured not shown for veterans aged $65+$ due to small cell sizes.

gaps in financial protection provided to older adults by even these popular insurance programs. Additionally, the ACA contained few reforms targeting Medicare enrollees, and concordantly we did not observe an improvement in financial protection among older veterans with non-VHA primary coverage. In comparison, older veterans with VHA as primary payer had better financial protection pre-ACA, and this advantage increased post-ACA. The reasons for this improvement are unclear from our data, but one possibility is that dualinsured older veterans are increasingly using their VHA coverage (whose cost sharing is lower and adjusted to income) preferentially over their Medicare benefits. For example, a recent study using VHA and Medicare claims found that from 2003 to 2014, Medicare-enrolled veterans increasingly relied on the VHA for their primary care (25 to $35 \%$ ), specialty care (14 to $22 \%$ ), and surgical care (15 to $22 \%$ ). ${ }^{39}$ Additionally, the VHA's decision to make expensive hepatitis $\mathrm{C}$ antivirals available to veterans at low cost in 2014 may have further protected some older veterans from catastrophic expenditures. $^{40}$

Lastly, several areas stand out as drivers of inadequate financial protection for veterans in the post-ACA period. Dental care was a leading source of out-of-pocket spending for insured veterans of all ages with catastrophic expenditures, likely because not all veterans with VHA coverage are eligible for VHA dental benefits, ${ }^{41}$ less than half of state Medicaid programs cover comprehensive dental care for adults, ${ }^{42}$ and traditional Medicare lacks a dental benefit entirely. ${ }^{43}$ Prescription drugs were another leading driver of spending, consistent with the known high patient cost of medications ${ }^{44}$ and the fact that Medicare Part D requires enrollees to pay medication deductibles and coinsurance without an out-of-pocket cap. ${ }^{45}$ Younger veterans with VHA coverage appeared relatively protected from prescription drug spending, consistent with prior research linking VHA coverage with lower cost-related medication nonadherence. ${ }^{40}$ Home healthcare costs were significant among older veterans, which may be attributable to limited VHA coverage for home care, ${ }^{46}$ lack of Medicare coverage for most non-skilled home-based services (which are captured in MEPS), ${ }^{47}$ and the heightened financial vulnerability faced by homebound seniors. ${ }^{48,49}$ Finally, outpatient visits were the largest driver of out-of-pocket spending among younger veterans with VHA coverage. Since outpatient copays within the VHA are limited to $\$ 15-50$ per visit, ${ }^{16}$ this likely reflects dual-insured (VHA and non-VHA) veterans seeking services from community providers, resulting in higher patient cost sharing. ${ }^{50,51}$

\section{Limitations}

Our study has several limitations. First, we are unable to identify veterans with forms of military discharge other than honorable, who may experience greater financial risk due to ineligibility for veterans' benefits. Second, MEPS follows respondents for at most 2 years, preventing longitudinal analysis of individual veterans whose insurance coverage changed. Third, although we adjust for unemployment in our multivariable models, broader economic trends in the US, including gains in employment and income, may explain some of the decrease in catastrophic expenditures among veterans over the study period. Fourth, while our models adjust for available socio-demographic characteristics, self-reported health, and census region, some residual confounding is possible, for example, due to redistribution of veterans to lower-cost areas within census regions during the study period. Fifth, because our definition of catastrophic health expenditures includes 
spending from all family members (as established by prior studies ${ }^{11,15}$ ), our findings may include some spillover effects of the ACA on non-veteran family members. Finally, since MEPS spending estimates do not include medical debt, postacute skilled nursing facility stays, or long-term nursing home care, our analysis likely underestimates some veterans' true financial hardship.

\section{CONCLUSIONS}

While coverage and financial protection have improved for younger veterans after ACA implementation, over 1.5 million veterans per year continue to experience catastrophic household spending due to healthcare costs, of whom over 1.2 million are aged 65 or older. Policy initiatives that could contribute to addressing this issue include adoption of Medicaid expansion in the 12 states that have not yet done so, outreach to encourage eligible veterans to enroll in VHA health benefits, and efforts to assist uninsured and underinsured veterans who are ineligible for VHA benefits to enroll in Medicaid or subsidized Marketplace insurance. Additionally, Congress could consider legislation expanding Medicare and Medicaid to include a dental benefit, which enjoys broad public support, ${ }^{43,52}$ or relieving the burdensome costs of home care for older veterans both with and without VHA benefits.

Both the future of the ACA and strategies to improve veterans' access to healthcare remain hotly debated, with the ACA's individual mandate eliminated beginning January 2019 and the VA MISSION Act passed in June 2018, which aimed to further expand veterans' ability to use their VHA benefits at non-VHA facilities. In this context, our findings provide new evidence that policymakers should consider strategies to further improve financial risk protection for veterans.

Acknowledgements: The authors thank Dr. Carlos Oronce for his feedback on the manuscript.

Corresponding Author: Charles Liu, MD, MS; Department of Surgery, Stanford University School of Medicine, Stanford, CA, USA (e-mail: cliu1@stanford.edu).

Supplementary Information The online version contains supplementary material available at https://doi.org/10.1007/s11606-02106807-4.

Funding Drs. Liu, Scannell, and Kenison are supported by the National Clinician Scholars Program at the University of California, Los Angeles and by the VA Office of Academic Affiliations through the VA/National Clinician Scholars Program. The contents do not represent the views of the US Department of Veterans Affairs or the United States Government.

\section{Declarations:}

Conflict of Interest: The authors declare that they do not have a conflict of interest.

\section{REFERENCES}

1. Peterson-Kaiser Family Foundation Health System Tracker. Per capita out-of-pocket expenditures, 1970-2018 [cited 2020 April 7]. Available from: https://www.healthsystemtracker.org/indicator/access-affordability/out-of-pocket-spending/.

2. Kirzinger A, Muñana C, Wu B, et al. Data Note: Americans' Challenges with Health Care Costs: Kaiser Family Foundation; June 2019 [cited 2020 March 2]. Available from: https://www.kff.org/health-costs/issuebrief/data-note-americans-challenges-health-care-costs/.

3. Himmelstein DU, Warren E, Thorne D, et al. Illness and injury as contributors to bankruptcy. Health Aff (Millwood). 2005; Suppl Web Exclusives:W5-63-w5-73.

4. Himmelstein DU, Thorne D, Warren E, et al. Medical bankruptcy in the United States, 2007: results of a national study. Am J Med. 2009; 122(8):741-6.

5. Obama B. United States Health Care Reform: Progress to Date and Next Steps. JAMA. 2016;316(5):525-32.

6. Tolbert $\mathbf{J}$, Orgera $\mathbf{K}$, Singer $\mathbf{N}$, et al. Key Facts about the Uninsured Population: Kaiser Family Foundation; Dec 13, 2019 [cited 2020 April 7]. Available from: https://www.kff.org/uninsured/issue-brief/key-factsabout-the-uninsured-population/.

7. Uberoi N, Finegold $\mathbf{K}$, Gee E. Issue Brief: Health Insurance Coverage and the Affordable Care Act, 2010-2016: Department of Health and Human Services, Office of the Assistant Secretary for Planning and Evaluation; March 3, 2016 [cited 2020 April 7]. Available from: https:// aspe.hhs.gov/system/files/pdf/187551/ACA2010-2016.pdf.

8. Frean M, Gruber J, Sommers BD. Premium subsidies, the mandate, and Medicaid expansion: Coverage effects of the Affordable Care Act. J Health Econ. 2017;53:72-86.

9. Miller S, Wherry LR. Health and Access to Care during the First 2 Years of the ACA Medicaid Expansions. N Engl J Med. 2017;376(10):947-56.

10. Sommers BD, Maylone B, Blendon RJ, et al. Three-Year Impacts Of The Affordable Care Act: Improved Medical Care And Health Among LowIncome Adults. Health Aff (Millwood). 2017;36(6):1119-28.

11. Goldman AL, Woolhandler S, Himmelstein DU, et al. Out-of-Pocket Spending and Premium Contributions After Implementation of the Affordable Care Act. JAMA Intern Med. 2018;178(3):347-55.

12. Goldman AL, McCormick D, Haas JS, et al. Effects Of The ACA's Health Insurance Marketplaces On The Previously Uninsured: A QuasiExperimental Analysis. Health Aff (Millwood). 2018;37(4):591-9.

13. Liu C, Tsugawa Y, Weiser TG, et al. Association of the US Affordable Care Act With Out-of-Pocket Spending and Catastrophic Health Expenditures Among Adult Patients With Traumatic Injury. JAMA Netw Open. 2020;3(2):e200157

14. Liu C, Maggard-Gibbons M, Weiser TG, et al. Impact of the Affordable Care Act Insurance Marketplaces on Out-of-Pocket Spending among Surgical Patients. Ann Surg. 2020.

15. Gotanda H, Jha AK, Kominski GF, et al. Out-of-pocket spending and financial burden among low income adults after Medicaid expansions in the United States: quasi-experimental difference-in-difference study. BMJ. 2020;368:m40.

16. US Department of Veterans Affairs. VA health care copay rates 2020 [cited 2020 April 7]. Available from: https://www.va.gov/health-care/copayrates/.

17. National Center for Veterans Analysis and Statistics. VA Utilization Profile, FY 2016: US Department of Veterans Affairs; November 2017 [cited 2020 April 22]. Available from: https://www.va.gov/vetdata/docs/QuickFacts/ VA_Utilization_Profile.PDF.

18. Chokshi DA, Sommers BD. Universal health coverage for US veterans: a goal within reach. Lancet. 2015;385(9984):2320-1.

19. Machlin SR, Muhuri P. Statistical Brief \#508: Characteristics and Health Care Expenditures of VA Health System Users versus Other Veterans, 2014-2015 (Combined): AHRQ Medical Expenditure Panel Survey; January 2018 [cited 2020 April 7]. Available from: https://meps.ahrq. gov/data_files/publications/st508/stat508.shtml.

20. Thomas JL, Wilk JE, Riviere LA, et al. Prevalence of mental health problems and functional impairment among active component and National Guard soldiers 3 and 12 months following combat in Iraq. Arch Gen Psychiatry. 2010;67(6):614-23.

21. Gates MA, Holowka DW, Vasterling JJ, et al. Posttraumatic stress disorder in veterans and military personnel: epidemiology, screening, and case recognition. Psychol Serv. 2012;9(4):361-82.

22. Boudreaux M, Barath D, Blewett LA. Recent Changes in Health Insurance Coverage for Urban and Rural Veterans: Evidence from the First Year of the Affordable Care Act. Mil Med. 2019;184(1-2):e76-e82. 
23. Ohl ME, Carrell M, Thurman A, et al. "Availability of healthcare providers for rural veterans eligible for purchased care under the veterans choice act". BMC Health Serv Res. 2018;18(1):315.

24. Knowlton LM, Dehghan MS, Arnow K, et al. The impact of Medicaid expansion on trauma-related emergency department utilization: A national evaluation of policy implications. J Trauma Acute Care Surg. 2020;88(1):59-69.

25. Dworsky M, Farmer CM, Shen M. Veterans' Health Insurance Coverage Under the Affordable Care Act and Implications of Repeal for the Department of Veterans Affairs. Rand Health Q. 2018;7(3):5.

26. Kelley AT, Tipirneni R, Levy H. Changes in Veterans' Coverage and Access to Care Following the Affordable Care Act, 2011-2017. Am J Public Health. 2019;109(9):1233-5.

27. Agency for Healthcare Research and Quality. MEPS HC-201: 2017 Full Year Consolidated Data File Documentation. 2019 [cited 2020 April 2]. Available from: https://meps.ahrq.gov/data_stats/download_data/pufs/ h201/h201doc.shtml.

28. Collins SR, Bhupal HK, Doty MM. Health Insurance Coverage Eight Years After the ACA: Fewer Uninsured Americans and Shorter Coverage Gaps, but More Underinsured: Commonwealth Fund; February 7, 2019 [cited 2020 January 11]. Available from: https://www. commonwealthfund.org/publications/issue-briefs/2019/feb/health-insurance-coverage-eight-years-after-aca.

29. US Census Bureau. Current Population Survey (CPS) Subject Definitions: Family. [updated February 27, 2019; cited 2019 July 3]. Available from: https://www.census.gov/programs-surveys/cps/technical-documentation/subject-definitions.html\#family.

30. US Census Bureau. How the Census Bureau Measures Poverty. [updated August 16, 2018; cited 2019 July 3]. Available from: https://www. census.gov/topics/income-poverty/poverty/guidance/poverty-measures.html.

31. Bureau of Labor Statistics. Archived Consumer Price Index Detailed Reports [updated October 31, 2018; cited 2019 July 4]. Available from: https://www.bls.gov/cpi/tables/detailed-reports/home.htm.

32. Agency for Healthcare Research and Quality. Using Appropriate Price Indices for Analyses of Health Care Expenditures or Income Across Multiple Years. February 2019 [cited 2020 January 11]. Available from: https://meps.ahrq.gov/about_meps/Price_Index.shtml.

33. Internal Revenue Service. Questions and Answers on Employer Shared Responsibility Provisions Under the Affordable Care Act. 2018 [cited 2019 February 21]. Available from: https://www.irs.gov/affordable-care-act/ employers/questions-and-answers-on-employer-shared-responsibilityprovisions-under-the-affordable-care-act.

34. Brooks T, Wagnerman $\mathbf{K}$, Artiga $\mathbf{S}$, et al. Medicaid and CHIP Eligibility, Enrollment, Renewal, and Cost Sharing Policies as of January 2018: Findings from a 50-State Survey: Kaiser Family Foundation; March 2018 [cited 2018 December 9]. Available from: https://www.kff.org/medicaid/ report/medicaid-and-chip-eligibility-enrollment-renewal-and-cost-sharing-policies-as-of-january-2018-findings-from-a-50-state-survey/.

35. Mattocks KM, Yehia B. Evaluating the Veterans Choice Program: Lessons for Developing a High-performing Integrated Network. Med Care. 2017;55 Suppl 7 Suppl 1:1-3.

36. Liu C, Gotanda $\mathbf{H}$, Khullar D, et al. The Affordable Care Act's Insurance Marketplace Subsidies Were Associated With Reduced Financial Burden For US Adults. Health Aff (Millwood). 2021;40(3):496-504.

37. Keith K. What It Means To Cover Preexisting Conditions: Health Affairs Blog; September 11, 2020 [cited 2021 March 7]. Available from: https:// www.healthaffairs.org/do/10.1377/hblog20200910.609967/full/.
38. Centers for Medicare and Medicaid Services. Affordable Care Act Implementation FAQs - Set 12 - Limitations on Cost-Sharing under the Affordable Care Act [cited 2021 March 7]. Available from: https://www. cms.gov/CCIIO/Resources/Fact-Sheets-and-FAQs/aca_implementation_faqs 12 .

39. Liu CF, Batten A, Wong ES, et al. Fee-for-Service Medicare-Enrolled Elderly Veterans Are Increasingly Voting with Their Feet to Use More VA and Less Medicare, 2003-2014. Health Serv Res. 2018;53 Suppl 3(Suppl Suppl 3):5140-58.

40. Gaffney A, Bor DH, Himmelstein DU, et al. The Effect Of Veterans Health Administration Coverage On Cost-Related Medication Nonadherence. Health Aff (Millwood). 2020;39(1):33-40.

41. US Department of Veterans Affairs. VA Dental Care. April 30, 2020 [cited 2020 May 6]. Available from: https://www.va.gov/health-care/about-vahealth-benefits/dental-care/.

42. US Department of Health and Human Services. Does Medicaid cover dental care? May 18, 2012 [cited 2020 May 6]. Available from: https:// www.hhs.gov/answers/medicare-and-medicaid/does-medicaid-coverdental-care/index.html.

43. Solway E, Sweier D, Kullgren JT. New Poll Demonstrates Broad Support for a Medicare Dental Benefit Among Older Adults: JAMA Health Forum; 2020 [cited 2020 May 6]. Available from: https://jamanetwork.com/ channels/health-forum/fullarticle/2765362.

44. Kennedy J, Wood EG. Medication Costs and Adherence of Treatment Before and After the Affordable Care Act: 1999-2015. Am J Public Health. 2016;106(10):1804-7.

45. Kaiser Family Foundation. An Overview of the Medicare Part D Prescription Drug Benefit. November 13, 2019 [cited 2020 May 12]. Available from: https://www.kff.org/medicare/fact-sheet/an-overview-of-themedicare-part-d-prescription-drug-benefit/.

46. US Department of Veterans Affairs. VA Aid and Attendance benefits and Housebound allowance. August 2019 [cited 2020 April 11]. Available from: https://www.va.gov/pension/aid-attendance-housebound/.

47. Centers for Medicare and Medicaid Services. Home health services: Medicare.gov; [cited 2020 May 21]. Available from: https://www.medicare.gov/coverage/home-health-services.

48. Johnson RW, Wang CX. The Financial Burden Of Paid Home Care On Older Adults: Oldest And Sickest Are Least Likely To Have Enough Income. Health Aff (Millwood). 2019;38(6):994-1002.

49. Ornstein KA, Leff B, Covinsky KE, et al. Epidemiology of the Homebound Population in the United States. JAMA Intern Med. 2015; 175(7):1180-6.

50. Dayoub EJ, Medvedeva EL, Khatana SAM, et al. Federal Payments for Coronary Revascularization Procedures Among Dual Enrollees in Medicare Advantage and the Veterans Affairs Health Care System. JAMA Netw Open. 2020;3(4):e201451.

51. Coughlin SS, Young L. A review of dual health care system use by veterans with cardiometabolic disease. J Hosp Manag Health Policy. 2018;2.

52. Stabenow D, Paul R, Cardin BL. Letter to HHS Secretary Azar and CMS Administrator Verma Re: Medicare Coverage of Dental Treatment. September 20, 2018 [cited 2020 May 11]. Available from: https: / /www.cardin. senate.gov/imo/media/doc/Azar\%20Dental\%20Letter\%209212018.pdf.

Publisher's Note: Springer Nature remains neutral with regard to jurisdictional claims in published maps and institutional affiliations. 